\title{
Frequency of hypergraphia in temporal lobe epilepsy: an index of interictal behaviour syndrome
}

\author{
H S A CHDEV AND S G W X M A N \\ From the Department of Neurology, Veterans Administration Medical Center and \\ Stanford University School of Medicine, Palo Alto, California
}

S UMMARY Frequency and degree of hypergraphia were studied in order to assess interictal behaviour change in temporal lobe epilepsy. Patients with temporal lobe epilepsy tended to reply more frequently to a standard questionnaire, and wrote extensively (mean: 1301 words) as compared to others (mean: 106 words). The incidence of temporal lobe epilepsy was $73 \%$ in patients exhibiting hypergraphia compared to $17 \%$ in patients without this trait. These findings suggest that hypergraphia may be a quantitative index of behaviour change in temporal lobe epilepsy.

The question of behavioural changes in patients with temporal lobe epilepsy (TLE) has received considerable attention. However, while hyperemotionalism, obsessionalism, religiosity, altered sexual behaviour, circumstantiality and hypergraphia have been described, ${ }^{1-9}$ their relation to temporal lobe dysfunction remains controversial. ${ }^{1011}$ Only a few studies have attempted to quantify these behavioural changes, ${ }^{2}{ }^{10-12}$ but Bear and Fedio were able to quantify and relate personality traits to a right or left temporal lobe focus. ${ }^{13}$ Hypergraphia is one of the relatively more obvious traits of the interictal behaviour syndrome.$^{67}$ We have attempted to measure this trait and to identify its specificity to any particular types of seizure disorder.

\section{Methods}

A letter was sent to all patients who had been admitted to hospital at PAVAMC from 1972 to 1978 , whose discharge index card listed "epilepsy" or "seizure disorder" as the primary or secondary diagnosis. The letter asked the patient to " . . . describe to the best of your ability, your present state of health, understanding of the disease (seizure disorder) and the changes in your life resulting from it. You may choose

Address for reprint requests: Dr Stephen G Waxman, Neurological Unit (127), Veterans Administration Medical Center, 3801 Miranda Avenue, Palo Alto, CA 94304, USA.

Accepted 21 January 1981 to write as much as you wish, in any form, on any kind of paper." A return envelope was included. Thus we attempted to make the question as broad as possible and to leave a great deal of flexibility for the patient to reply. Letters were mailed to 63 patients. Nine letters were returned undelivered, 21 answers were received. Four responses (from relatives) indicated that patients were deceased. Thus, we presume that 33 patients received letters but did not reply. We divided our patient population into three groups: (1) those who changed residence without leaving any forwarding address, (2) those who did not reply, (3) those who did reply. EEG reports and case histories for all patients were reveiwed. All patients had been evaluated by neurologists other than those conducting the present study. The letters of 17 patients who replied were divided (without knowledge of the histories or EEG reports) on the basis of content [description of ictal or interictal events, reference to "meaning" or "significance" of seizures, philosophical, ethical or religious themes and style (calligraphy, use of unusual symbols or drawings, length)] into three groups: (A) probable interictal syndrome, (B) possible interictal syndrome, (C) no evidence of interictal syndrome (table 1). The person who rated the replies did not know the number or proportion of TLE patients in the response sample. In addition, a second division was based upon the number of words (table 2).

\section{Results}

Number of patients responding of 63 patients to whom letters were mailed, 33 patients did not reply and nine did not receive letters. Of the 33 patients 
Table 1

\begin{tabular}{|c|c|c|c|c|}
\hline Groups & $\begin{array}{l}\text { Temporal lobe epilepsy } \\
\text { EEG }+ \\
\text { History }+\end{array}$ & $\begin{array}{l}\text { Major motor seizures } \\
\text { EEG }+ \\
\text { History }+\end{array}$ & $\begin{array}{l}\text { Abnormal but non- } \\
\text { epileptiform EEG } \\
\text { History-as mentioned }\end{array}$ & $\begin{array}{l}\text { Normal EEG } \\
\text { History-as mentioned }\end{array}$ \\
\hline $\begin{array}{l}\text { Group } 1 \\
\quad N=9 \\
\text { Letters returned undelivered }\end{array}$ & 1-Left temporal focus & $\begin{array}{l}\text { 2-Generalised bursts of } \\
\text { epileptiform activity }\end{array}$ & $\begin{array}{l}\text { 2-Diffuse slowing on EEG; } \\
\text { no focus. Metabolic } \\
\text { encephalopathy }\end{array}$ & $\begin{array}{l}\text { 4-Withdrawal } \\
\text { seizures }\end{array}$ \\
\hline $\begin{array}{l}\text { Group } 2 \\
\text { No }=33 \\
\text { Did not reply }\end{array}$ & $\begin{array}{l}\text { 3-Left temporal focus } \\
\text { 1-Right temporal focus } \\
\text { 2-Bitemporal foci }\end{array}$ & $\begin{array}{l}\text { 2-Generalised epileptiform } \\
\text { activity; corticoreticular } \\
\text { epilepsy }\end{array}$ & $\begin{array}{l}\text { 14-Diffuse, nonfocal, } \\
\text { nonspecific abnor- } \\
\text { malities } \\
\text { Withdrawal seizures } \\
\text { 4-Diffuse slowing } \\
\text { Metabolic encepha- } \\
\text { lopathies }\end{array}$ & $\begin{array}{l}\text { 3-Maior motor } \\
\text { seizures } \\
\text { 1-Temporal lobe } \\
\text { 3-Withdrawal } \\
\text { seizures }\end{array}$ \\
\hline $\begin{array}{l}\text { Group } 3 \\
\text { No=17 } \\
\text { Replied }\end{array}$ & $\begin{array}{l}\text { 4-Bitemporal foci } \\
\text { 1-Left temporal foci } \\
\text { 2-Right temporal foci }\end{array}$ & $\begin{array}{l}\text { 2-Generalised epilep- } \\
\text { tiform activity; No focus }\end{array}$ & $\begin{array}{l}\text { 2-Diffuse, nonfocal, } \\
\text { nonspecific abnor- } \\
\text { malities; } \\
\text { Withdrawal seizures } \\
\text { 1-Diffuse slowing } \\
\text { Metabolic encephalopat }\end{array}$ & $\begin{array}{l}\text { 2-Temporal lobe } \\
\text { epilepsy } \\
\text { 3-Withdrawal } \\
\text { seizures } \\
\text { hy }\end{array}$ \\
\hline
\end{tabular}

Table 2

\begin{tabular}{|c|c|c|c|c|}
\hline Subgroups of Group 3 & Case No. Word count & $\begin{array}{l}\text { Temporal lobe epilepsy } \\
\text { EEG }+ \\
\text { History }+\end{array}$ & $\begin{array}{l}\text { Major motor seizure } \\
\text { EEG-nonspecific } \\
\text { nonepileptiform } \\
\text { History-as mentioned }\end{array}$ & $\begin{array}{l}\text { Normal EEG } \\
\text { History-as mentioned }\end{array}$ \\
\hline
\end{tabular}

Subgroup A

No $=2$

Probable interictal No $1-5540$ words

Subgroup B

No $=9$

Possible interictal syndrome

Subgroup C
No=6
No evidence of interictal
change

No $1-475$ words
No $2-470$ words

No 2- 470 words

No 3- 403 words

No 4- 230 words

No 5- 212 words

No 6- 170 words

No $7-128$ words

No 8- 125 words

No 9- 120 words

No $1-110$ words

No 2- 112 words

No 3- 88 words

No 4- 85 words

No 5 - 54 words

No 6- 33 words
Bitemporal foci

Bitemporal foci

Right temporal focus

Temporal lobe epilepsy

Left temporal focus

Bitemporal foci

Major motor seizure, no aura

Right temporal focus

Temporal lobe epilepsy

Withdrawal seizure

Withdrawal seizure

Bitemporal foci

One major motor seizure

Metabolic encephalopathy

Withdrawal seizure

Withdrawal seizure

Withdrawal seizure who did not reply, seven had clinical diagnosis of TLE; all but one also had positive EEG. Group 1table 1 indicates the diagnosis in patients who did not receive the letter ( 1 of 9 had TLE). In group 3 (those who replied): nine had a diagnosis of TLE with epileptiform activity present in EEG in seven. Thus, of 17 patients who replied, nine $(53 \%)$ had TLE; while of 33 patients who did not reply, only seven $(21 \%)$ had TLE. There was a significant $(p<0.05$; chi-square $=5 \cdot 19$ ) overrepresentation of TLE among the responders. The proportion of temporal lobe epileptics replying was $56 \%$, compared to $24 \%$ of patients with nontemporal lobe epilepsy.

Characteristics of the response Further evidence that there might be differences between the temporal lobe as compared to the nontemporal lobe population, was provided by an examination of the responses. All patients classified, without knowledge of clinical diagnosis or EEG findings, as "probable interictal syndrome," had clinical evidence of temporal lobe epilepsy and EEG evidence of bitemporal foci; among the "possible interictal syndrome" patients, 67\% had TLE (table 2). The proportion of TLE in all patients with hypergraphia (patients classified as either probable or possible interictal syndrome) is $8: 11(73 \%)$. This is greater than the proportion of TLE in patients without evidence of interictal changes (subgroup $C$, table 2, which was $1: 6(17 \%)$.

A possibly more objective index (number of words in responses) also was examined. Responses classified as "probable interictal syndrome" were 5540 and 4200 words in length. Responses classified as "possible 
interictal syndrome" (subgroup B, table 2, ranged from 120 to 475 words (mean $=259$ words). Subgroup C (no evidence of interictal change) used 33 to 112 words (mean $=78$ words). For TLE, the mean response was 1301 words, with a median of 403 . In contrast, for nontemporal lobe epileptics, the mean response was 106 words, with a median of 100 . Quantitative differences between the groups were significant $(p<0.001$, Wilcoxon rank test).

\section{Discussion}

The occurrence of personality changes in patients with TLE has been suggested by a number of workers $^{1-9} 1213$ but remains unproven. ${ }^{1011}$ Waxman and Geschwind ${ }^{7}$ noted hypergraphia, circumstantiality, hyperreligiosity, hypersexuality and described these as part of the interictal behavioural syndrome in TLE. They pointed out that this behaviour did not occur in all patients with TLE and that when behavioural changes occurred, they were not necessarily maladaptive. Rodin also noted a high incidence of behavioural change in TLE. ${ }^{8}$ Bear and Fedio $^{13}$ studied 18 different personality traits in 27 temporal lobe epileptics and 21 controls, and on the basis of these personality traits, 26 temporal lobe epileptics and 21 non-epileptics could be correctly diagnosed.

We studied one trait, hypergraphia, in a population of epileptics, by examining the response to a standard stimulus. Patients with TLE tended to reply more frequently: out of the 17 who replied nine had TLE. Out of the 33 patients who did not reply, only seven had TLE (table 1 ). The two definite hypergraphics (classified on the basis of examination of the response [without knowledge of clinical diagnosis or EEG findings]) had clinical features of complex partial seizure, and bitemporal foci on EEG. Of the nine patients with possible interictal syndrome, six were diagnosed as TLE (four with positive EEG). Examination of the writings of patients A1 and A2 (probable interictal syndrome) was consistent with the changes described previously. ${ }^{6}$ Moreover, neither of these two patients had any difficulties with memory (other than during the seizures), comprehension or speech disorder. Onset of seizures in these two patients occurred about eight years prior to this study and neither of them has shown any evidence of psychosis to date. It should also be pointed out that hypergraphia does not appear to be related to intelligence. While all temporal lobe epileptics do not exhibit hypergraphia, the existence of hypergraphia in a patient with seizures should alert the physician to the possibility of TLE. This conclusion, based on quantitative data, supports previous conclusions ${ }^{6} 7$ based on observation of individual patients. While the small sample size in our population makes it difficult to analyse fully the incidence of hypergraphia, it nevertheless appears to be a good index with which to elicit the presence of interictal behaviour syndrome and may present at least one quantitative parameter of this behaviour change in patients with TLE.

We thank Norman Geschwind, MD for helpful discussions and comments on the manuscript.

\section{References}

1 Gibbs FA. Ictal and non-ictal psychiatric disorders in temporal lobe epilepsy. J Nerv Ment Dis 1951; 113:522-8.

2 Slater E, Beard AW. The schizophrenia-like psychoses of epilepsy. Br J Psychiatry 1963; 109: 95-150.

3 Glaser G. The problem of psychosis in psychomotor temporal lobe epileptics. Epilepsia 1964; 5:271-88

4 Geschwind N. Effects of temporal lobe surgery on behavior. N Engl J Med 1973; 289:480-1.

5 Blumer D. Temporal lobe epilepsy and its psychiatric significance. Psychiat Aspects Neurol Dis, Seminars in Psychiatry 1975; 171-98.

6 Waxman SG, Geschwind N. Hypergraphia in temporal lobe epilepsy. Neurology (Minneap) 1974 ; 24:629-36.

7 Waxman SG, Geschwind N. The interictal behavior syndrome of temporal lobe epilepsy. Arch Gen Psychiatry 1975; 32:1580-6.

8 Rodin EA, Katz M, Lennon K. Differences between patients with temporal lobe seizures and those with other forms of epileptic attacks. Epilepsia 1976; 17:313-20.

9 Blumer D, Walker EA. Sexual behavior in temporal lobe epilepsy. Arch Neurol 1967; 16:313-20.

10 Small IG, Small IF, Hyden MP. Further psychiatric investigations of patients with temporal and non-temporal lobe epilepsy. Am J Psychiatry 1966; 123:303-10.

11 Stevens J. Interictal clinical manifestations of complex partial seizures. Adv Neurol 1975; 11: 85-112.

12 Dongier S. Statistical study of clinical and electroencephalographic manifestations of 536 psychotic episodes occurring in 516 epileptics between clinical seizures. Epilepsia 1959; 1:117.

13 Bear D, Fedio P. Quantitative analysis of interictal behavior in temporal lobe epilepsy. Arch Neurol 1977; 34:454-67. 